\title{
Editorial
}

\section{Biomarker and Translational Prostate Cancer Research}

\author{
Andreas Doll, ${ }^{1}$ Jeremy Clark, ${ }^{2}$ and Colleen Nelson ${ }^{3}$ \\ ${ }^{1}$ Biomedical and Translational Oncology Research Unit, Institut de Recerca Vall d'Hebron, Edifici Collserola, \\ Passeig de la Vall d'Hebron, 119-129 Barcelona, Spain \\ ${ }^{2}$ Cancer Genetics, University of East Anglia, Norwich, Norfolk NR4 s7TJ, UK \\ ${ }^{3}$ Australian Prostate Cancer Research Centre, Brisbane, QLD 4102, Australia \\ Correspondence should be addressed to Andreas Doll; andreas.doll@vhir.org
}

Received 17 November 2014; Accepted 17 November 2014

Copyright (C) 2015 Andreas Doll et al. This is an open access article distributed under the Creative Commons Attribution License, which permits unrestricted use, distribution, and reproduction in any medium, provided the original work is properly cited.

The existing clinical biomarkers for prostate cancer (PCa) are not ideal, since they cannot specifically differentiate between those patients who should be treated immediately and those who should avoid overtreatment. Current screening techniques lack specificity, and a decisive diagnosis of PCa is based on prostate biopsy. Although PCa screening is widely utilized nowadays, two-thirds of the biopsies performed are still unnecessary. Thus, the discovery of noninvasive PCa biomarkers remains an urgent unmet medical need. Once metastasized, there is still no curative therapy. A better understanding of sustained androgen receptor signalling in castration resistant prostate cancer (CRPC) has now led to the development of more effective therapies. We need a better understanding of the molecular and cellular aspects of prostate carcinogenesis and progression. Identification of cancer initiating cells and therapies against these populations is a promising way forward to fight this disease.

\section{Acknowledgments}

The editors thank the authors for their efforts and time spent for each manuscript. The lead editor would like to thank all editors for the time spent in reviewing, assigning reviews, and commenting on submitted manuscripts. The editors hope that this special issue will prove useful to investigators, policy makers, and veterinarians involved in the study of respiratory diseases of small ruminants. At last but not least, the expertise and cooperation of editorial team are highly acknowledged.

\section{Andreas Doll Jeremy Clark Colleen Nelson}




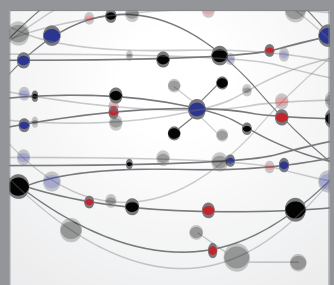

The Scientific World Journal
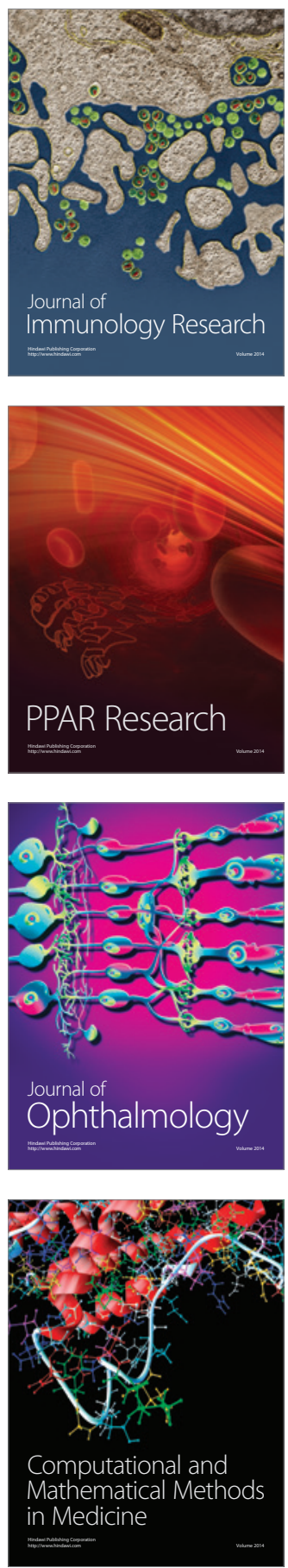

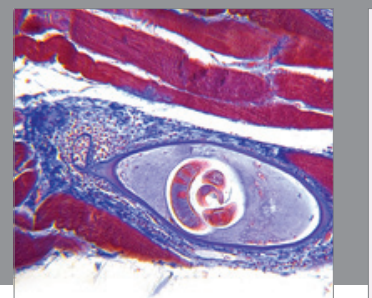

Gastroenterology

Research and Practice
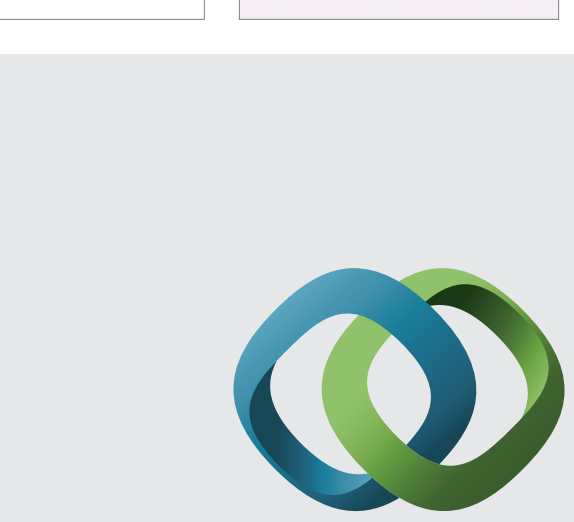

\section{Hindawi}

Submit your manuscripts at

http://www.hindawi.com
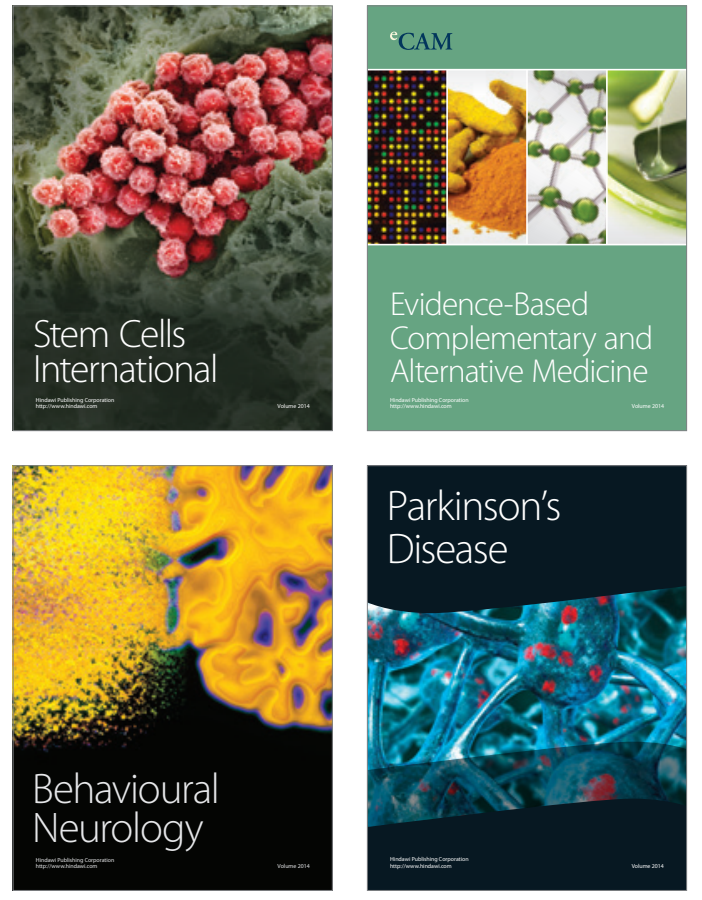
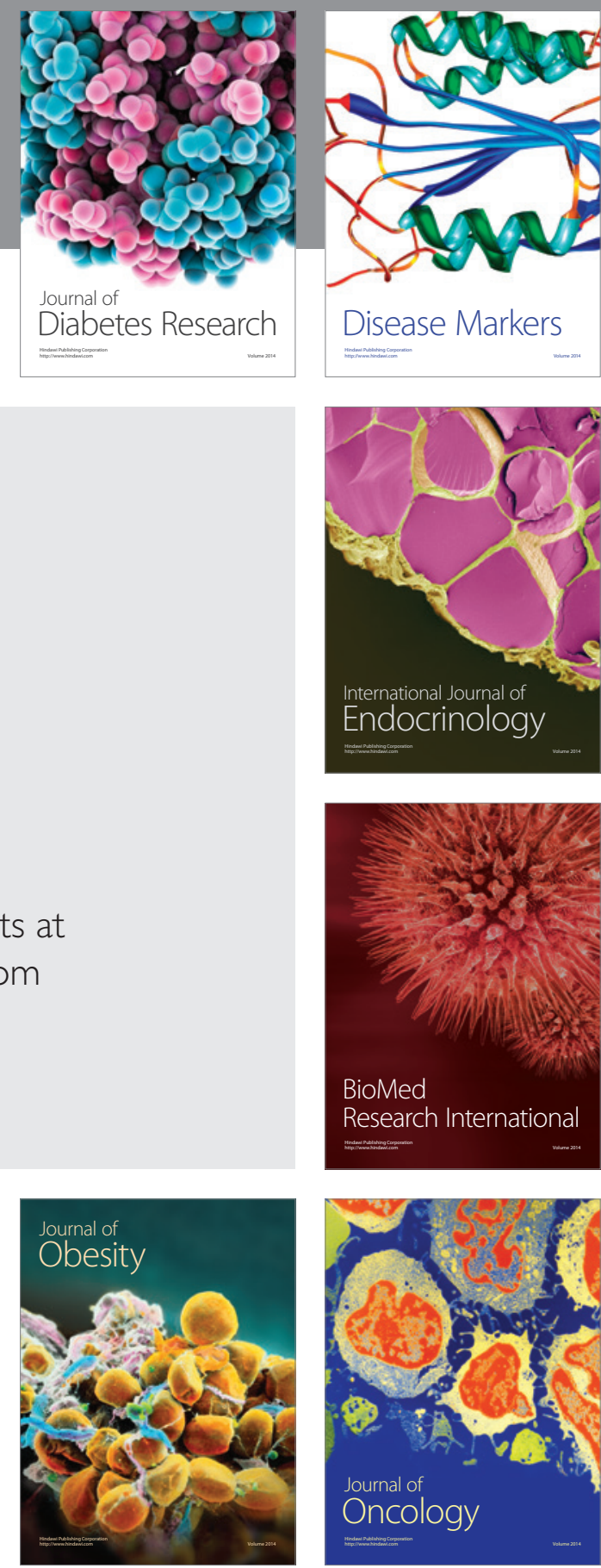

Disease Markers
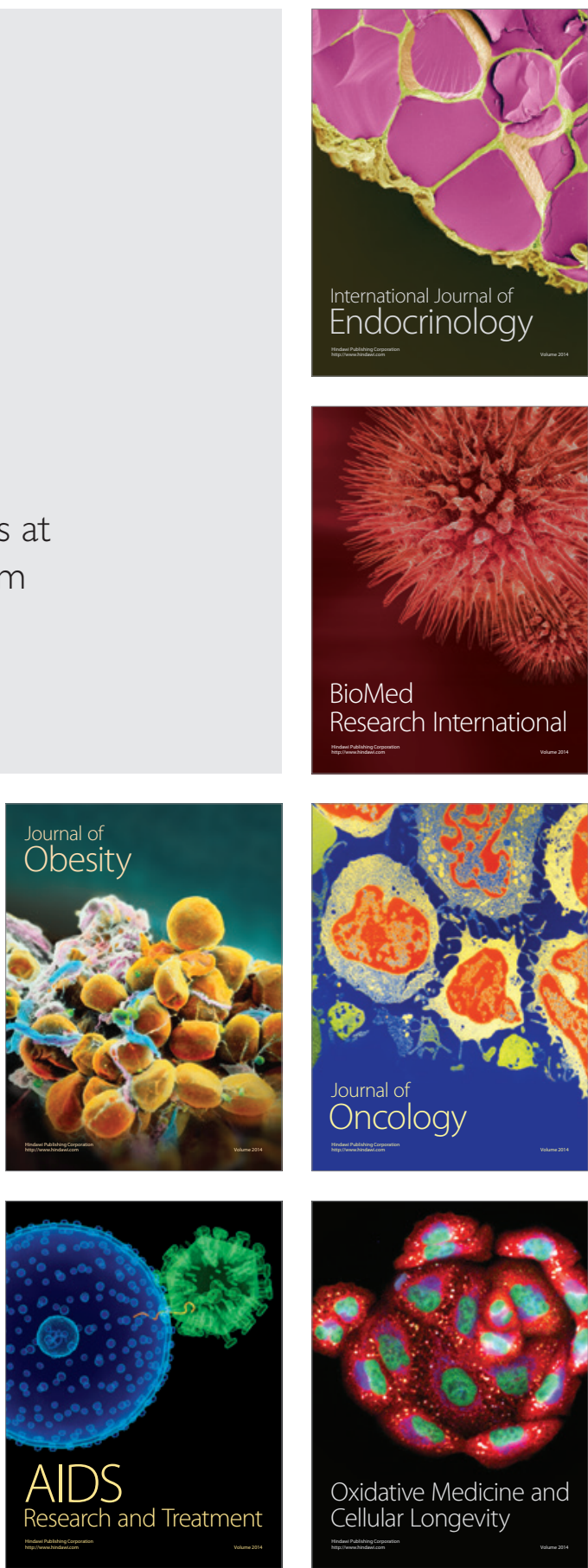